\title{
The Regeneration Cycle of Cobalt Chemical Conversion Waste Liquid on Aluminum Alloys
}

\author{
Di MA ${ }^{1}{ }^{*}$, Zhenzhen XU ${ }^{1}$, Xuejiao LV ${ }^{1}$, Shubai LI $^{2}$, Jilei WANG ${ }^{1}$, Zairan YU ${ }^{1}$, Zebo TANG ${ }^{1}$, \\ Guohua ZHANG ${ }^{1}$
}

${ }^{1}$ School of Chemistry \& Environmental Engineering, Jiangsu University of Technology, Changzhou, China

${ }^{2}$ Department of Chemical Engineering, Changzhou Institute of Engineering Technology, Changzhou, China

crossref $\mathrm{http}: / / \mathrm{dx}$.doi.org/10.5755/j01.ms.25.2.19131

Received 27 September 2017; accepted 22 March 2018

\begin{abstract}
In this research, the regeneration cycle of cobalt chemical conversion waste liquid, the effects of oxidizing agents on solution service life, and the influence of oxidizing agents on the treatment of waste liquid was studied by the electrochemical performance test. The scanning electron microscopy (SEM) and electrochemical properties analysis was used to study conversion coatings. It was determined that the best oxidizing agent for the cobalt chemical conversion waste liquid was $9 \mathrm{~g} / \mathrm{L} \mathrm{KBrO}_{3}$. Conversion coatings were thicker and had a higher density when the specific gravity of reclaimed liquid and stock solution was between 1:2 and 1:1.

Keywords: aluminum alloys, chemical conversion, waste liquid, reutilization.
\end{abstract}

\section{INTRODUCTION}

Currently aluminum alloys are the most commonly used class of non-ferrous metals in the industry [1-4]. But aluminum alloy surface is easily damaged, and prone to corrosion in the air [5]. In order to increase the corrosion resistance of aluminum alloys, a series of surface chemical conversion treatment measures are completed. In the past, hexavalent chromium coating was widely used [6-9], then countries around the world take strict measures to limit or disable chromate conversion solution containing $\mathrm{Cr}^{6+}$, because it belongs to primary carcinogen [10-13]. In the present, aluminum alloy chemical conversion coating tends to excellent film performance, non-toxic process, and environmental protection $[14,15]$, such as permanganate conversion [16-18], Ce-Mo-based conversion [19-21], rare-earth conversion [22-24], Ti/Zr based conversion $[25,26]$, silicate conversion $[27,28]$, cobalt conversion, and more.

In many conversion systems, only the cobalt chemical conversion system can completely replace the $\mathrm{Cr}^{6+}[29,30]$. Because the trivalent cobalt ions are strong oxidizers, and the redox potential of $\mathrm{Co}^{3+} / \mathrm{Co}^{2+}$ is the closest to the equilibrium potential of $\mathrm{Cr}^{6+} / \mathrm{Cr}^{3+}$. Its conversion coating has great corrosion resistance and excellent adhesion strength. However, it has a high content of cobalt and large amounts of cobalt are used in aluminum alloy cobalt chemical conversion waste liquid. Therefore, recycling and repeated use of cobalt in waste liquid has high significance in research and market prospects.

In this article, the regeneration cycle of cobalt chemical conversion waste liquid, the effects of film forming promoters on solution service life, and the influence of oxidizing agents on the treatment of waste liquid were studied by electrochemical performance test. If the regeneration process was developed successfully, it also can be established on the basis of other electroplating system of regeneration cycle processes, and will also be significant in the environmental and economic benefits.

\section{EXPERIMENTAL}

The experimental material was 1020 pure aluminium with $20 \mathrm{~mm} \times 50 \mathrm{~mm} \times 0.25 \mathrm{~mm}$ dimensions. The samples were first degreased, then soaked in $\mathrm{NaOH}$ and $\mathrm{HNO}_{3}$ to remove the surface contamination, rinsed and dried between each step of the operation.

The $\mathrm{Co}^{2+}$ concentration was $6.5021 \mathrm{mg} / \mathrm{mL}$, and added 3 12 g/L different types of waste recycling oxidants, which contained $\mathrm{KClO}_{3}, \mathrm{KClO}_{4}$, and $\mathrm{KBrO}_{3}$, then the pretreated samples were put into the above conversion solutions at $80^{\circ} \mathrm{C}$ for 30 minutes. Finally, the treated recovered liquid was used as a replenisher, mixed with the new liquid in a ratio of $5: 1$ to $1: 5$, and then the above film forming experiments were repeated.

The electrochemical measurements were performed on a PGSTAT $302 \mathrm{~N}$ electrochemical workstation, that was used to analyze the corrosion resistance of conversion film. Scanning electron microscopy (SEM, Hitachi S-3400NII) was working at $15 \mathrm{kV}$, and used to study the aluminium alloys surface morphology and microstructure of cobalt chemical conversion coating.

\section{RESULTS AND DISCUSSION}

\subsection{Different concentration and type of oxidants effect on conversion coatings}

To select a suitable oxidant, the corrosion resistance of the conversion film can be judged by analyzing the comparative electrochemical experimental data. The

\footnotetext{
* Corresponding author. Tel.: +86-15951207428.

E-mail address:madi@jsut.edu.cn (D. Ma)
} 
relative corrosion resistance parameters of the Tafel curves in Fig. 1 are shown in Table 1.

Table 1. Corrosion parameters of Tafel curves in Fig. 1

\begin{tabular}{|c|c|c|c|c|}
\hline \multirow{2}{*}{, $\mathrm{g} / \mathrm{L}$} & Oxidant & $E_{\text {corr }, \mathrm{V}}$ & $I_{\text {corr, } \mu \mathrm{A} \cdot \mathrm{cm}^{-2}}$ & $R_{\mathrm{p}}, \mathrm{k} \Omega \cdot \mathrm{cm}^{-2}$ \\
\hline \multirow{2}{*}{3} & $\mathrm{KClO}_{4}$ & -0.16 & $0.49 \times 10^{-2}$ & 325.19 \\
\cline { 2 - 5 } & $\mathrm{KClO}_{3}$ & -0.76 & 5.17 & 11.79 \\
\cline { 2 - 5 } & $\mathrm{KBrO}_{3}$ & -0.74 & 11.03 & 26.96 \\
\hline \multirow{3}{*}{6} & $\mathrm{KClO}_{4}$ & -0.62 & 1.17 & 7.39 \\
\cline { 2 - 5 } & $\mathrm{KClO}_{3}$ & -0.59 & 2.11 & 21.33 \\
\cline { 2 - 5 } & $\mathrm{KBrO}_{3}$ & -0.63 & 4.64 & 16.49 \\
\hline \multirow{2}{*}{9} & $\mathrm{KClO}_{4}$ & -0.60 & 2.26 & 11.04 \\
\cline { 2 - 5 } & $\mathrm{KClO}_{3}$ & -0.64 & 2.29 & 14.06 \\
\cline { 2 - 5 } & $\mathrm{KBrO}_{3}$ & -0.72 & $0.11 \times 10^{-2}$ & 351.36 \\
\hline \multirow{2}{*}{12} & $\mathrm{KClO}_{4}$ & -0.57 & 1.76 & 13.73 \\
\cline { 2 - 5 } & $\mathrm{KClO}_{3}$ & -0.74 & 2.57 & 12.31 \\
\cline { 2 - 5 } & $\mathrm{KBrO}_{3}$ & -0.64 & 0.24 & 112.25 \\
\hline
\end{tabular}

In general, the magnitude of the value of the corrosion current intuitively reflects the ability of the conversion film to protect the substrate. When the amount of oxidant was $3 \mathrm{~g} / \mathrm{L}$, the corrosion resistance of $\mathrm{KClO}_{4}$ was better than that of $\mathrm{KClO}_{3}$ and $\mathrm{KBrO}_{3}$. When the concentration was $6 \mathrm{~g} / \mathrm{L}$, the $R_{\mathrm{p}}$ (polarization resistance) of $\mathrm{KClO}_{4}$ was much smaller than $\mathrm{KClO}_{3}$ and $\mathrm{KBrO}_{3}$. When $\mathrm{KClO}_{3}$ was used as a recycling oxidant, the $E_{\text {corr }}$ (corrosion potential) and $R_{\mathrm{p}}$ were much higher than $\mathrm{KClO}_{4}$, and the corrosion resistance of the conversion film was the best. When the amount of oxidant was $9-12 \mathrm{~g} / \mathrm{L}$, the corrosion current and the polarization resistance of the conversion film were both larger than

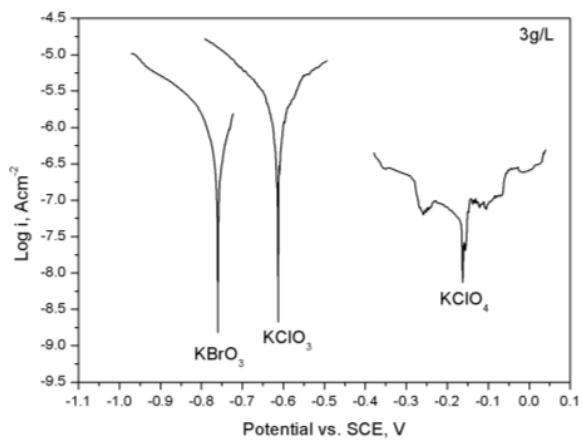

a

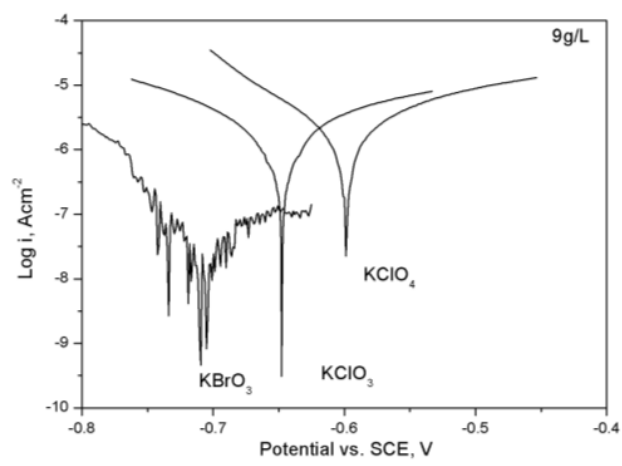

c
$\mathrm{KClO}_{4}$ and $\mathrm{KClO}_{3}$, when $\mathrm{KBrO}_{3}$ was used. However, when the amount was $9 \mathrm{~g} / \mathrm{L}$, the $\mathrm{I}_{\text {corr }}$ (corrosion current) of $\mathrm{KBrO}_{3}$ reached the lowest at $0.0011 \mu \mathrm{A} \cdot \mathrm{cm}^{-2}$, but the highest polarization resistance of the conversion film was achieved at $351.36 \mathrm{k} \Omega \cdot \mathrm{cm}^{-2}$, and the corrosion coatings was the best.

Fig. 2 shows the equivalent circuit diagram. $R_{\mathrm{s}}$ is the solution resistance, which is between the reference electrode capillary and working electrode, $R_{\mathrm{p}}$ is the film resistor, and $\mathrm{CPE}$ is the dispersion effect on dual-capacity.

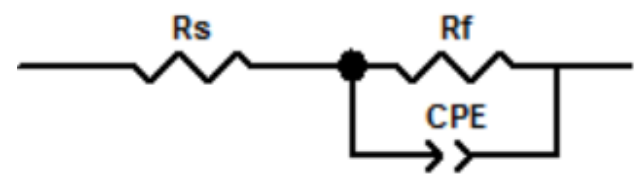

Fig. 2. Equivalent circuit diagram of conversion coating in 3.5 wt. $\% \mathrm{NaCl}$ solution

As shown in Fig. 3, the EIS diagram of conversion films, which were using $\mathrm{KClO}_{4}$ and $\mathrm{KBrO}_{3}$, had only one capacitance arc when the concentration of the oxidants in $3 \mathrm{~g} / \mathrm{L}$, and used $\mathrm{KClO}_{4}$ had the largest capacitive arc diameter. While the EIS diagram of the conversion films with $\mathrm{KClO}_{3}$ had two capacitive arcs, the low-frequency capacitance arc is not complete and the capacitive arc diameter of the low-frequency region is larger than that of the middle-high frequency region. The EIS diagram of conversion films, which were using $\mathrm{KClO}_{4}$ and $\mathrm{KClO}_{3}$, had only one capacitance arc when the concentration of the oxidants was $6 \mathrm{~g} / \mathrm{L}$.

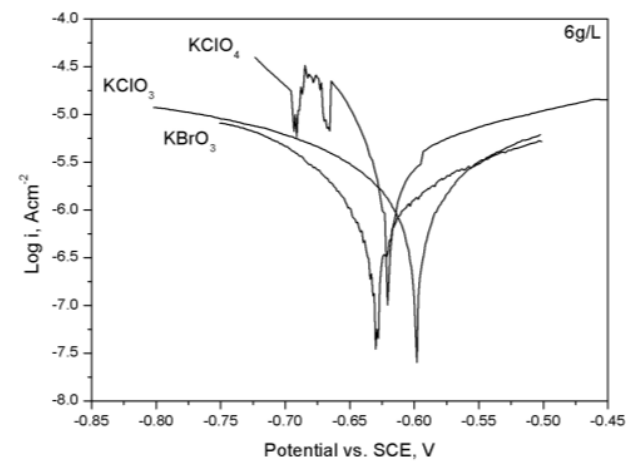

b

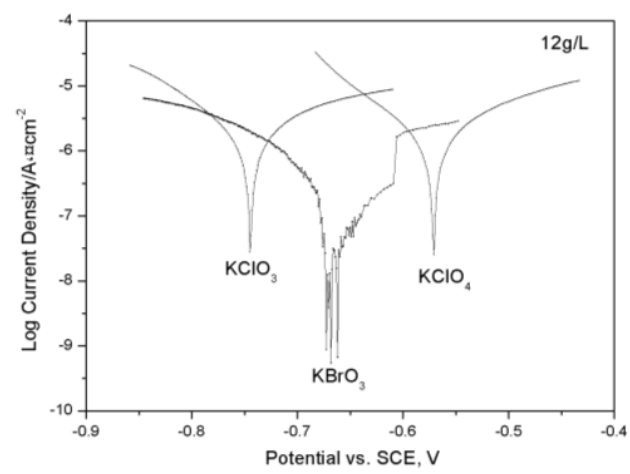

d

Fig. 1. Tafel curves of the conversion coatings prepared with different concentrations of $\mathrm{KClO}_{3}, \mathrm{KClO}_{4}$, and $\mathrm{KBrO}_{3}$ to treated liquid wastes: $\mathrm{a}-3 \mathrm{~g} / \mathrm{L} ; \mathrm{b}-6 \mathrm{~g} / \mathrm{L} ; \mathrm{c}-9 \mathrm{~g} / \mathrm{L} ; \mathrm{d}-12 \mathrm{~g} / \mathrm{L}$ 

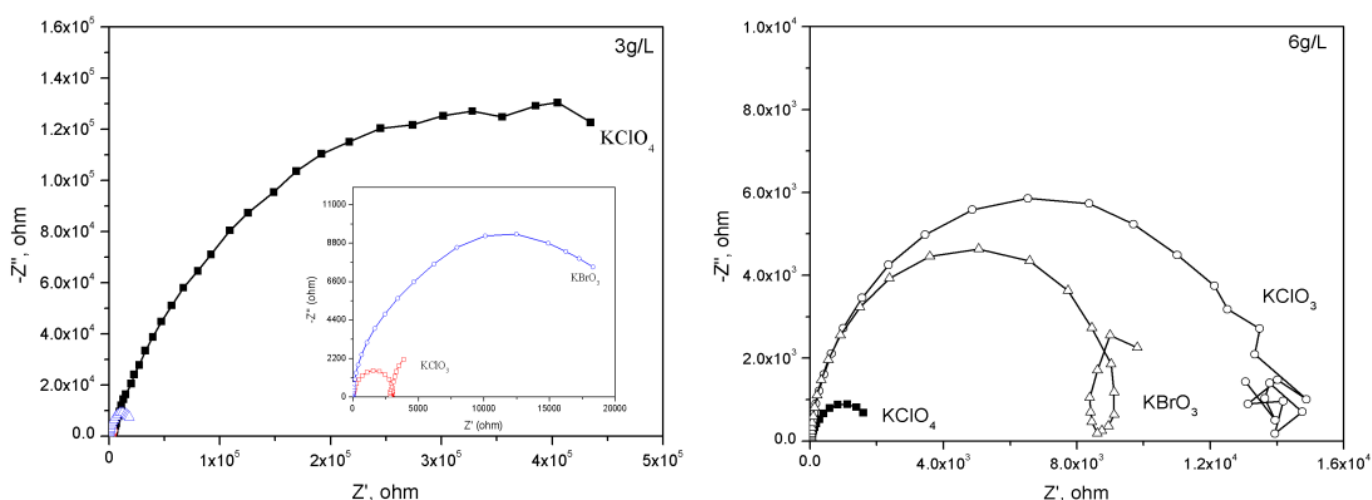

a

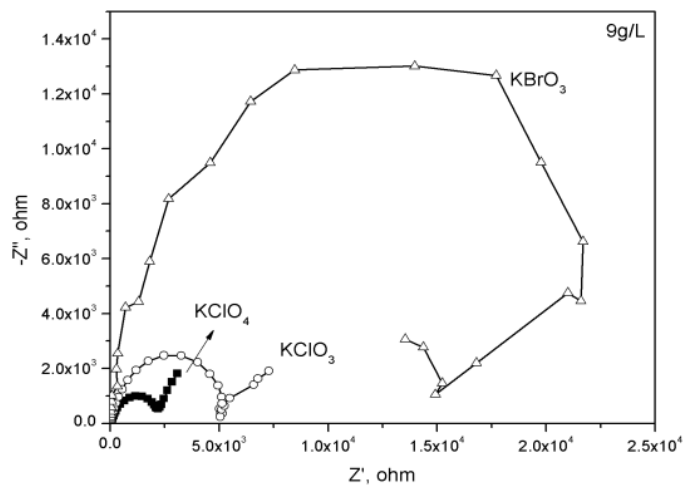

b

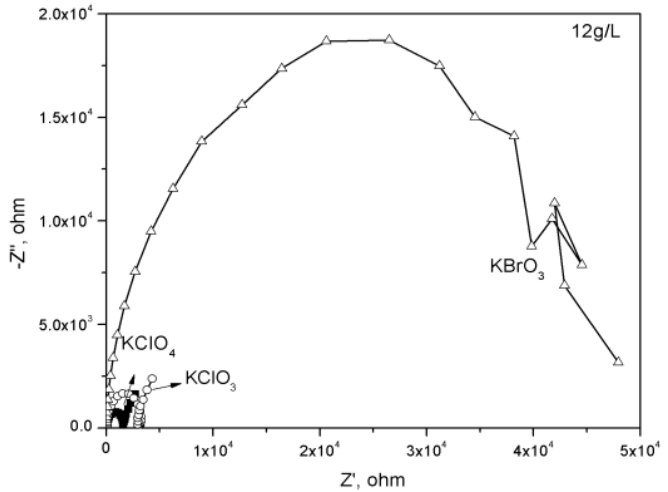

d

Fig. 3. The EIS of the conversion coatings prepared by different concentrations of $\mathrm{KClO}_{3}, \mathrm{KClO}_{4}$ and $\mathrm{KBrO}_{3}$ in $3.5 \% \mathrm{NaCl}$ solution: $\mathrm{a}-3 \mathrm{~g} / \mathrm{L} ; \mathrm{b}-6 \mathrm{~g} / \mathrm{L} ; \mathrm{c}-9 \mathrm{~g} / \mathrm{L} ; \mathrm{d}-12 \mathrm{~g} / \mathrm{L}$

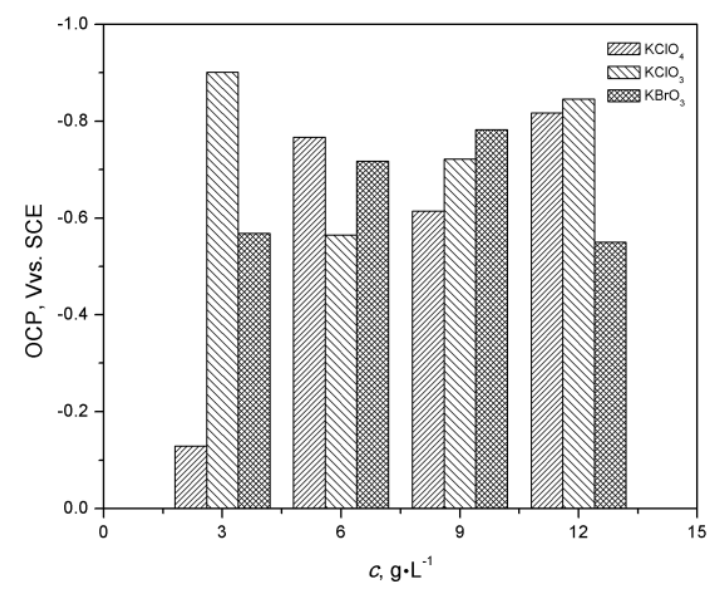

Fig. 4. Open-circuit potential of the conversion coatings prepared by treating the waste liquid with different oxidants at different concentration in $3.5 \% \mathrm{NaCl}$ solution

Additionally, the conversion film using $\mathrm{KClO}_{3}$ had the largest capacitive arc diameter in the medium-high frequency area, and the conversion film using $\mathrm{KBrO}_{3}$ had a smaller capacitive arc diameter in the low frequency area. The EIS diagram of conversion films, which were using $\mathrm{KClO}_{3}$ and $\mathrm{KClO}_{4}$, were composed of two capacitance arcs when the concentration of the oxidants was $9 \mathrm{~g} / \mathrm{L}$. An inductive arc appeared in the low frequency region of the conversion films, which were using $\mathrm{KBrO}_{3}$, and the largest arc appeared in the medium-high frequency region. However, when $\mathrm{KClO}_{4}$ and $\mathrm{KClO}_{3}$ were used, there were two capacitive arcs in the EIS diagram, and the capacitive arc diameter in the medium-high frequency regions were smaller than that of $\mathrm{KBrO}_{3}$.
The the open-circuit potential(OCP) of the coating was the highest when the oxidant was $3 \mathrm{~g} / \mathrm{L} \mathrm{KClO}_{4}$. The OCP of $\mathrm{KClO}_{3}$ was $-0.565 \mathrm{~V}$ when the concentration increased to $6 \mathrm{~g} / \mathrm{L}$, which was lower than $\mathrm{KClO}_{4}$ and $\mathrm{KBrO}_{3}$. The OCP of $12 \mathrm{~g} / \mathrm{L} \mathrm{KBrO}_{3}$ was $-0.55 \mathrm{~V}$, which was lower than $\mathrm{KClO}_{4}$ and $\mathrm{KClO}_{3}$.

\subsection{Concentration of reclaimed liquid effect on conversion coatings}

Fig. 5 showed the chemical conversion curves in different specific gravity. Table 2 showed the $E_{\text {corr }}, I_{\text {corr }}$, and $R_{\mathrm{p}}$ parameters obtained from the polarization curve.

Table 2. Corrosion parameters of Tafel curves in Fig. 4

\begin{tabular}{|c|c|c|c|}
\hline $\begin{array}{c}\text { Specific gravity } \\
\text { of recovering } \\
\text { liquid }\end{array}$ & $E_{\text {corr, }} \mathrm{V}$ & $I_{\text {corr, }} \mu \mathrm{A} \cdot \mathrm{cm}^{-2}$ & $R_{\mathrm{p}}, \mathrm{k} \Omega \cdot \mathrm{cm}^{-2}$ \\
\hline $1 / 6$ & -0.53 & 1.33 & 42.99 \\
\hline $1 / 3$ & -0.56 & 1.00 & 45.78 \\
\hline $1 / 2$ & -0.56 & 0.59 & 45.82 \\
\hline $2 / 3$ & -0.58 & 2.93 & 28.36 \\
\hline $5 / 6$ & -0.57 & 6.10 & 19.57 \\
\hline
\end{tabular}

The specific gravity of the reclaimed liquid equals the recovery in the liquid and the liquid mixing ratio, and the recovery in the liquid is the cobalt salt chemical conversion waste liquid after oxidation treatment. Under normal circumstances, the smaller the corrosion potential, the smaller the corrosion rate of the conversion coating, and the stronger the corrosion resistance of the cobalt conversion coating. The maximum $E_{\text {corr }}$ is $-0.53 \mathrm{~V}$ when the specific gravity of reclaimed liquid was $1 / 6$, and the minimum $E_{\text {corr }}$ 
is $-0.58 \mathrm{~V}$ when the specific gravity was $2 / 3$. As the proportion of the reclaimed liquid in the mixture increased, the $E_{\text {corr }}$ trend initially shifted positively, then shifted negatively and changed less. Contrarily, the $I_{\text {corr }}$ first decreased, then increased. The $I_{\text {corr }}$ was at a minimum and its' polarization resistance was maximal when the specific gravity was $1 / 2$. These results indicated that the corrosion resistance of cobalt chemical conversion coatings was the best under these conditions, and the corrosion rate of the coatings was the lowest in nature. When the specific gravity increased to $2 / 3$, the $I_{\text {corr }}$ decreased to $2.93 \mu \mathrm{A} \cdot \mathrm{cm}^{-2}$, and the polarization resistance value of the conversion coatings decreased. The $I_{\text {corr }}$ increases to $6.10 \mu \mathrm{A} \cdot \mathrm{cm}^{-2}$, the $\mathrm{R}_{\mathrm{p}}$ decreases to $19.57 \mathrm{k} \Omega \cdot \mathrm{cm}^{-2}$, and the corrosion resistance decreased significantly when the specific gravity reached $5 / 6$.

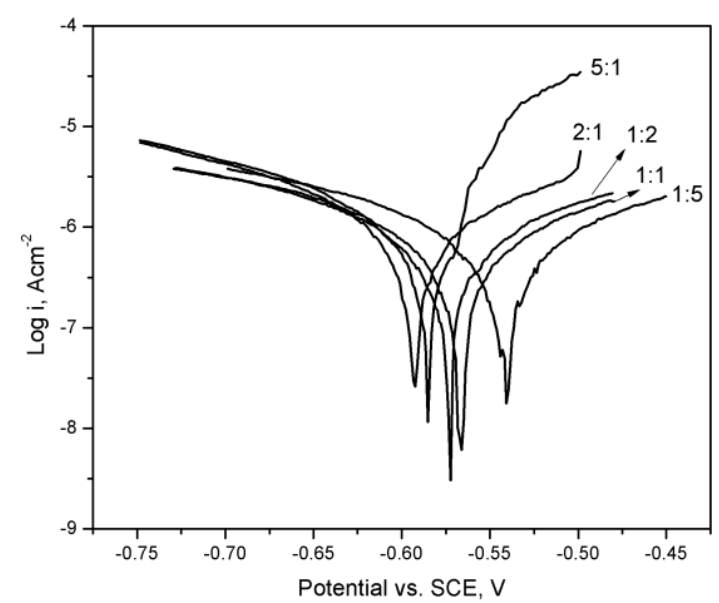

Fig. 5. Tafel curves of the conversion coatings prepared in $3.5 \%$ $\mathrm{NaCl}$ solution with different specific gravity

Fig. 6 shows the EIS in different proportions.

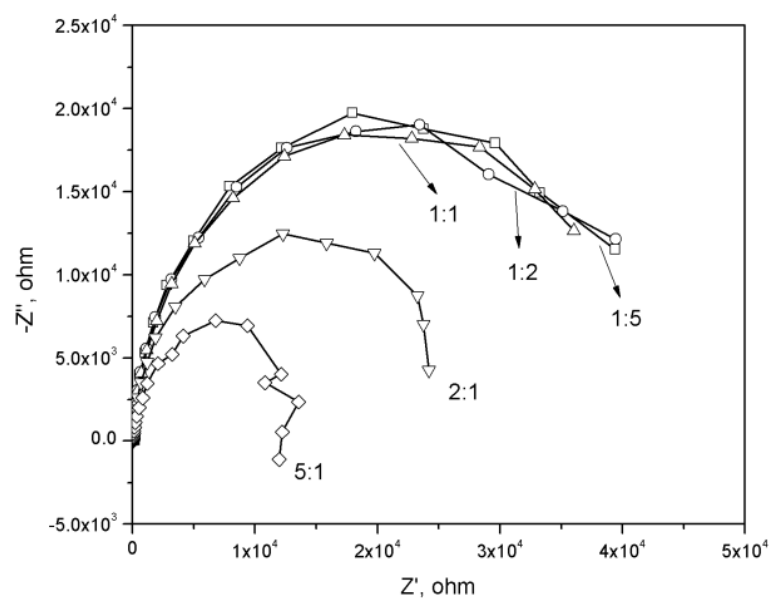

Fig. 6. The EIS of the conversion coatings prepared in $3.5 \% \mathrm{NaCl}$ solution with different specific gravity

When the specific gravity increases to about $1 / 2$, the capacitance arc diameter of the cobalt chemical conversion coatings in the middle frequency region is closer to the high frequency region, and without obvious changes. The capacitance arc diameter of the middle and high frequency regions began to decrease as the proportion of the reclaimed liquid in the mixed solution increased, and the lowfrequency region in the fourth quadrant showed significant inductive arc. It was indicated that the pitting corrosion occurs on the surface of the coatings, which led to the emergence of the inductance arc. That might be because the $\mathrm{pH}$ value of the solution decreased as the specific gravity of the reclaimed liquid increased, which leads to the appearance of $\mathrm{H}^{-}$, making small pores appear on the coatings surface.

Fig. 7 showa the change of the open-circuit potential value of the cobalt chemical conversion coatings prepared in the mixed solution of the different specific gravity. The open-circuit potential was the lowest at $0.552 \mathrm{~V}$ when the specific gravity of the reclaimed liquid in the mixed solution was $1 / 6$. The open-circuit potential value changes little with the increase of the specific gravity of the reclaimed liquid. The open-circuit potential value is reduced when the specific gravity was larger than $1 / 2$, and the change trend corresponded to the change trend of the AC impedance.

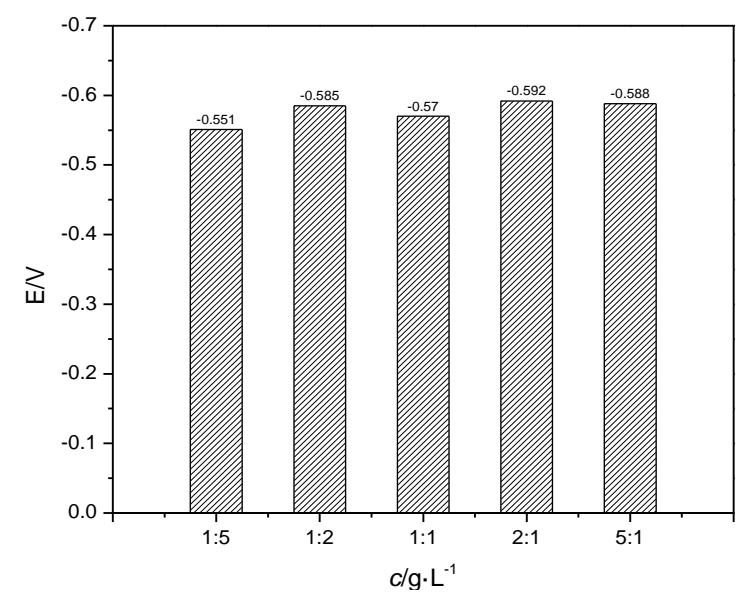

Fig. 7. Open-circuit potential of the conversion coatings prepared in $3.5 \% \mathrm{NaCl}$ solution in different specific gravity

As shown in Fig. 8, when the specific gravity was 1:6 (Fig. 8 a1 and a2), there was a small amount of sediment and a larger gap on the surface. When the specific gravity was 1:2 (Fig. 8 b1 and b2), there are some mulches and larger gaps appear on the coating surface. Simultaneously, the deposited layer of the conversion coatings is thicker and the outermost layer is looser. In Fig. $8 \mathrm{c} 1$ to e2, the surface of the coatings had small and uniform pores, but when the specific gravity was $1: 1$ to $2: 1$ (Fig. $8 \mathrm{c} 1-\mathrm{d} 2$ ), some of the holes were filled, resulting in them having a high density. It is noticeable in Fig. $8 \mathrm{f}$ that the conversion coatings prepared in the stock solution had a high density and a large amount of deposit on the surface. Additionally, the coating is thick and the outer layer is completely covered. Comparative to SEM, the closed area was the largest and the number of the voids was the least when the specific gravity was about 1:2, making it most reasonable to use the reclaimed liquid.

\section{DISCUSSION}

When $\mathrm{KClO}_{3}$ and $\mathrm{KClO}_{4}$ are chosen as oxidizer, a decomposition reaction will occur to produce $\mathrm{Cl}^{-}$, which will corrode the cobalt oxide in the film under acidic conditions. The main reaction equation is as follows [31, 32]:

$2 \mathrm{ClO}_{3}^{-}=2 \mathrm{Cl}^{-}+3 \mathrm{O}_{2} \uparrow ;$ 


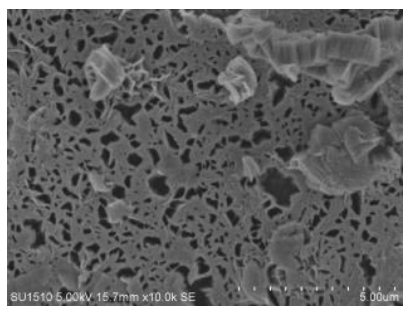

a1

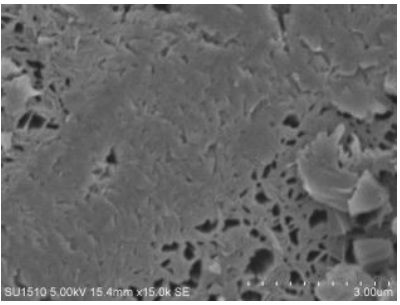

c1

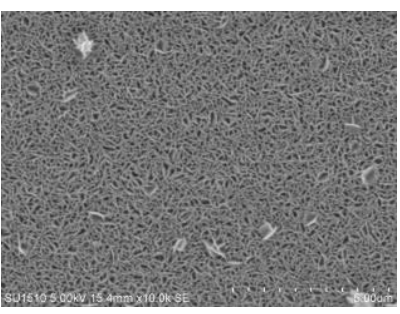

e1

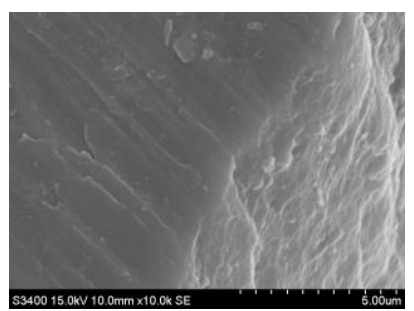

a2

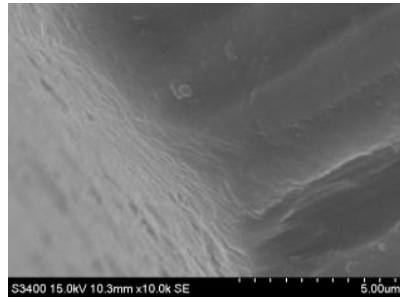

c2

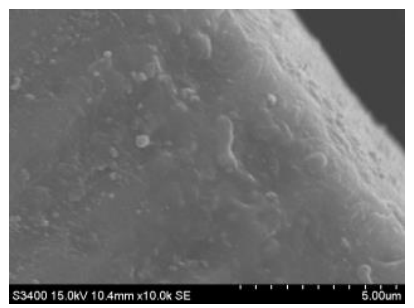

e2

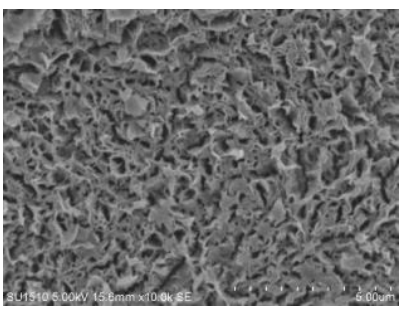

b1

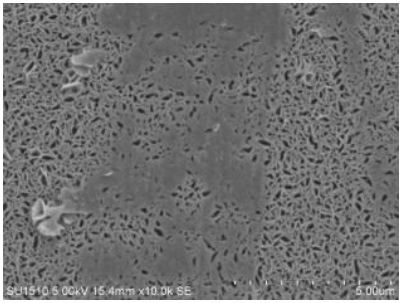

d1

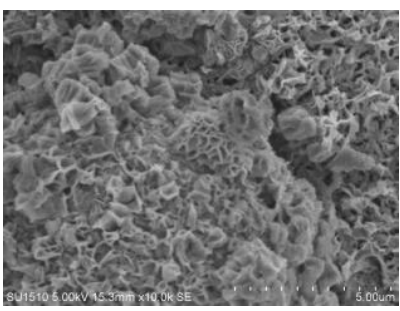

f1

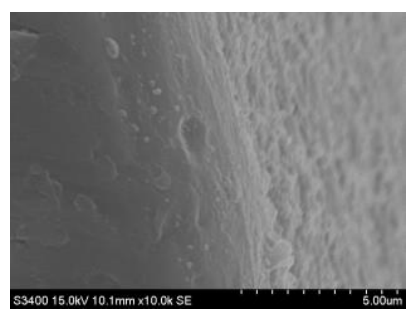

b2

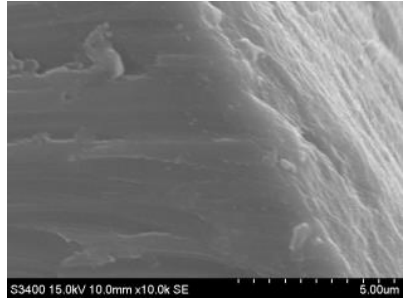

d2

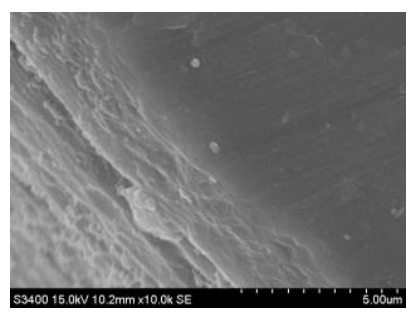

f2

Fig. 8. SEM micrographs showing the surface and cross-section morphology of conversion coatings prepared in mixture solution with different specific gravity, the specific gravity of reclaimed liquid and stock solution was: $a-1: 6 ; b-1: 2 ; c-1: 1 ; d-2: 1 ; e-5: 6$; $\mathrm{f}$-stock solution

$$
\begin{aligned}
& 2 \mathrm{ClO}_{4}^{-}=2 \mathrm{Cl}^{-}+2 \mathrm{O}_{2} \uparrow ; \\
& \mathrm{Co}_{2} \mathrm{O}_{3}+2 \mathrm{Cl}^{-}+6 \mathrm{H}^{+}=2 \mathrm{Co}^{2+}+\mathrm{Cl}_{2} \uparrow+3 \mathrm{H}_{2} \mathrm{O} ; \\
& 2 \mathrm{Co}^{2+}+\mathrm{O}_{2}+2 \mathrm{H}^{+}=2 \mathrm{Co}^{3+}+2 \mathrm{OH}^{-} .
\end{aligned}
$$

When the concentration of $\mathrm{KClO}_{3}$ and $\mathrm{KClO}_{4}$ is low, the $\mathrm{O}_{2}$ produced after the two are decomposed will convert bivalent cobalt in the conversion liquid to trivalent cobalt under acidic conditions, and the $\mathrm{pH}$ of the interface between the metal and the conversion liquid will be obtained. The recovery is favorable to the deposition of cobalt oxides with different valences, so the corrosion resistance of $\mathrm{KClO}_{3}$ and $\mathrm{KClO}_{4}$ is higher. The reaction equation is as follows [33]:

$2 \mathrm{Co}^{2+}+\mathrm{O}_{2}+2 \mathrm{H}^{+}=2 \mathrm{Co}^{3+}+2 \mathrm{OH}^{-}$.

The produced $\mathrm{O}_{2}$ is reacted with divalent cobalt under acidic conditions and converted to trivalent cobalt, resulting in the Eq. 4. Thus, after the addition of the oxidizing agent $\mathrm{NaBrO}_{3}$, the corrosion resistance of the film layer is gradually improved in the early stage of the cycle.

\section{CONCLUSIONS}

In the research the effect of oxidants on the cobalt chemical conversion liquid waste processing was studied. With the increase of oxidants' concentration, the electrochemical performance and corrosion parameters of $\mathrm{KBrO}_{3}$ prepared conversion coatings was better than that of
$\mathrm{KClO}_{4}$ and $\mathrm{KClO}_{3}$. The decomposition of $\mathrm{NaClO}_{3}$ and $\mathrm{NaClO}$ could produce $\mathrm{Cl}^{-}$, which will corrode $\mathrm{Co}_{2} \mathrm{O}_{3}$ and $\mathrm{Co}_{3} \mathrm{O}_{4}$ in the film layer, leading to poor corrosion resistance in the earlier film. While $\mathrm{NaBrO}_{3}$ could consume a part of $\mathrm{H}^{+}$, which is conducive to the deposition of $\mathrm{Co}_{2} \mathrm{O}_{3}$ and $\mathrm{Co}_{3} \mathrm{O}_{4}$.

The reclaimed liquid was mixed with the stock solution by a certain specific gravity to form conversion coatings, and the electrochemical test is carried out on the surface. When the specific gravity of reclaimed liquid and stock solution was between $1: 2$ and 1:1, the conversion coatings had a double membrane structure, the surface of unconsolidated layers had a high density. Therefore, the corrosion resistance of the conversion coatings was the best.

\section{Acknowledgments}

This work was sponsored by the Natural Science Foundation of the Jiangsu Higher Education Institutions (No.17KJA610002), Jiangsu Key Research and Social Development Project (No. BE2017649), Jiangsu Overseas Research \& Training Program for University Prominent Young \& Middle-aged Teachers and Presidents.

\section{REFERENCES}

1. Zhan, L., Ma, Z., Zhang, J., Tan, J., Yang, Z., Li, H. Stress Relaxation Ageing Behaviour and Constitutive Modelling of A 2219 Aluminium Alloy Under The Effect of 
an Electric Pulse Journal of Alloys and Compounds

2016: pp. 316-323.

https://doi.org/10.1016/j.jallcom.2016.04.051

2. Qi, J., Němcová, A., Walton, J.R., Zhou, X., Skeldon, P., Thompson, G.E. Influence of Pre- and Post-Treatments on Formation of a Trivalent Chromium Conversion Coating on AA2024 Alloy Thin Solid Films 616 2016: pp. 270-278. https://doi.org/10.1016/j.tsf.2016.08.044

3. Goebel, J., Ghidini, T., Graham, A.J. Stress-corrosion Cracking Characterisation of the Advanced Aerospace Al-Li 2099-T86 Alloy Materials Science and Engineering: A 673 2016: pp. $16-23$.

http://dx.doi.org/10.1016/j.msea.2016.07.013

4. Zhong, X., Wu, X., Jia, Y., Liu, Y. Self-repairing Vanadium-Zirconium Composite Conversion Coating for Aluminum Alloys Applied Surface Science $280(0)$ 2013: pp. $489-493$. http://dx.doi.org/10.1016/j.apsusc.2013.05.015

5. O'Keefe, M.J., Geng, S., Joshi, S. Cerium-based Conversion Coatings as Alternatives to Hex Chrome: RareEarth Compounds Provide Resistance Against Corrosion for Aluminum Alloys in Military Applications Metal Finishing 105 (5) 2007: pp. 25-28.

https://doi.org/10.1016/S0026-0576(07)80547-2

6. Bierwagen, G., Brown, R., Battocchi, D., Hayes, S. Active Metal-based Corrosion Protective Coating Systems for Aircraft Requiring No-Chromate Pretreatment Progress in Organic Coatings 67 (2) 2010: pp. 195-208. https://doi.org/10.1016/j.porgcoat.2009.10.031

7. Indumathi, S.N., Vasudevan, T., Sundarrajan, S., Subba Rao, B.V., Murthy, C.V.S., Yadav, D.R. Cadmiumand Chromate-free Coating Schemes for Corrosion Protection of 15CDV6 Steel Metal Finishing 109(3) 2011: pp. $15-21$. https://doi.org/10.1016/S0026-0576(11)00010-9

8. Cui, X.-j., Liu, C.-h., Yang, R.-s., Li, M.-t., Lin, X.-z., Gong, M. Phosphate Film Free of Chromate, Fluoride and Nitrite on AZ31 Magnesium Alloy and its Corrosion Resistance Transactions of Nonferrous Metals Society of China 22 (11) 2012: pp. 2713-2718. https://doi.org/10.1016/S1003-6326(11)61522-7

9. Bhargava, G., Allen, F. Self-Healing, Chromate-free Conversion Coating for Magnesium Alloys Metal Finishing 110 (4) 2012: pp. $32-38$.

https://doi.org/10.1016/S0026-0576(13)70127-2

10. Campestrini, P., van Westing, E.P.M., de Wit, J.H.W. Influence of Surface Preparation on Performance of Chromate Conversion Coatings on Alclad 2024 Aluminium Alloy: Part I: Nucleation and Growth Electrochimica Acta 46 (16) 2001: pp. $2553-2571$.

https://doi.org/10.1016/S0013-4686(01)00475-3

11. Liu, Y., Skeldon, P., Thompson, G.E., Habazaki, H., Shimizu, K. Chromate Conversion Coatings on Aluminium: Influences of Alloying Corrosion Science $46(2)$ 2004: pp. $297-312$. https://doi.org/10.1016/S0010-938X(03)00157-4

12. Liu, Y., Skeldon, P., Thompson, G.E., Habazaki, H., Shimizu, K. Chromate Conversion Coatings on AluminiumCopper Alloys Corrosion Science 47 (2) 2005: pp. $341-354$. https://doi.org/10.1016/S0010-938X(03)00157-4

13. Chidambaram, D., Clayton, C.R., Halada, G.P. The Role of Hexafluorozirconate in the Formation of Chromate Conversion Coatings on Aluminum Alloys Electrochimica Acta 51 (14) 2006: pp. 2862-2871.

\section{https://doi.org/10.1016/j.electacta.2005.08.022}

14. Kamaraj, K., $\quad$ Karpakam, V., $\quad$ Syed Azim, S., Sathiyanarayanan, S. Electropolymerised Polyaniline Films as Effective Replacement of Carcinogenic Chromate Treatments for Corrosion Protection of Aluminium Alloys Synthetic Metals $162(5-6)$ 2012: pp. 536-542. https://doi.org/10.1016/j.synthmet.2012.01.022

15. Twite, R.L., Bierwagen, G.P. Review of Alternatives to Chromate for Corrosion Protection of Aluminum Aerospace Alloys Progress in Organic Coatings 33 (2) 1998: pp. $91-100$. https://doi.org/10.1016/S0300-9440(98)00015-0

16. Zhao, M., Wu, S., An, P., Fukuda, Y., Nakae, H. Growth of Multi-elements Complex Coating on AZ91D Magnesium Alloy Through Conversion Treatment Journal of Alloys and Compounds $427(1-2)$ 2007: pp. 310-315. https://doi.org/10.1016/j.jallcom.2006.03.018

17. Zhang, H., Yao, G., Wang, S., Liu, Y., Luo, H. A ChromeFree Conversion Coating for Magnesium-Lithium Alloy by a Phosphate-Permanganate Solution Surface and Coatings Technology 202 (9) 2008: pp. 1825-1830. https://doi.org/10.1016/j.surfcoat.2007.07.094

18. Yoganandan, G., Balaraju, J.N. Synergistic Effect of V and Mn Oxyanions for the Corrosion Protection of Anodized Aerospace Aluminum Alloy Surface and Coatings Technology 252 (0) 2014: pp. 35-47. https://doi.org/10.1016/j.surfcoat.2014.04.062

19. Gorman, J.D., Johnson, S.T., Johnston, P.N., Paterson, P.J.K., Hughes, A.E. The Characterisation of CeMo-based Conversion Coatings on Al-Alloys: Part II Corrosion Science 38 (11) 1996: pp. 1977-1990. https://doi.org/10.1016/S0010-938X(96)00089-3

20. Hughes, A.E., Gorman, J.D., Paterson, P.J.K. The Characterisation of Ce-Mo-based Conversion Coatings on AlAlloys: Part I Corrosion Science 38 (11) 1996: pp. $1957-1976$. https://doi.org/10.1016/S0010-938X(96)00088-1

21. Mu, S., Du, J., Jiang, H., Li, W. Composition Analysis and Corrosion Performance of A Mo-Ce Conversion Coating on AZ91 Magnesium Alloy Surface and Coatings Technology 254 (0) 2014: pp. 364-370. https://doi.org/10.1016/j.surfcoat.2014.06.044

22. Xingwen, Y., Chunan, C., Zhiming, Y., Derui, Z., Zhongda, Y. Study of Double Layer Rare Earth Metal Conversion Coating on Aluminum Alloy LY12 Corrosion Science 43 (7) 2001: pp. 1283-1294. https://doi.org/10.1016/S0010-938X(00)00141-4

23. Han, Z., Zuo, Y., Ju, P., Tang, Y., Zhao, X., Tang, J. The Preparation and Characteristics of a Rare Earth/Nano- $\mathrm{TiO}_{2}$ Composite Coating on Aluminum Alloy by Brush Plating Surface and Coatings Technology $206(14)$ 2012: pp. 3264-3269. https://doi.org/10.1016/j.surfcoat.2012.01.027

24. Hamdy, A.S., Butt, D.P. Corrosion Mitigation of Rare-Earth Metals Containing Magnesium EV31A-T6 Alloy Via Chrome-Free Conversion Coating Treatment Electrochimica Acta 108 2013: pp. 852-859. https://doi.org/10.1016/j.electacta.2013.07.043

25. Wang, S.H., Liu, C.S., Shan, F.J. Corrosion Behavior of a Zirconium-Titanium Based Phosphonic Acid Conversion Coating on AA6061 Aluminium Alloy Acta Metallurgica Sinica (English Letters) 21 (4) 2008: pp. 269-274. https://doi.org/10.1016/S1006-7191(08)60048-4

26. Yi, A., Li, W., Du, J., Mu, S. Preparation and Properties of Chrome-free Colored Ti/Zr Based Conversion Coating on 
Aluminum Alloy Applied Surface Science 258 (16) 2012: pp. $5960-5964$.

https://doi.org/10.1016/j.apsusc.2011.12.045

27. Hamdy, A.S., Butt, D.P. Environmentally Compliant Silica Conversion Coatings Prepared by Sol-gel Method for Aluminum Alloys Surface and Coatings Technology 201 (1-2) 2006: pp. $401-407$.

https://doi.org/10.1016/j.surfcoat.2005.11.142

28. Bahri, H., Danaee, I., Rashed, G.R. The Effect of Curing Time and Curing Temperature on the Corrosion Behavior of Nanosilica Modified Potassium Silicate Coatings on AA2024 Surface and Coatings Technology $254(0)$ 2014: pp. $305-312$.

https://doi.org/10.1016/j.surfcoat.2014.06.041
29. Santa Coloma, P., Izagirre, U., $\quad$ Belaustegi, Y., Jorcin, J.B., Cano, F.J., Lapeña, N. Chromium-free Conversion Coatings Based on Inorganic Salts $(\mathrm{Zr} / \mathrm{Ti} / \mathrm{Mn} / \mathrm{Mo})$ for Aluminum Alloys Used in Aircraft Applications Applied Surface Science 345 2015: pp. 24-35.

30. Wei-Kun, C.,Ching-Yuan, B. The Effect of Chromic Sulfate Concentration and Immersion Time on the Structures and Anticorrosive Performance of The $\mathrm{Cr}$ (III) Conversion Coatings on Aluminum Alloys Applied Surface Science 1 (16) 2010: pp. 4924-4929.

http://dx.doi.org/10.1016/j.apsusc.2010.03 